\title{
Perencanaan Bangunan Kiln Menggunakan Metode Pracetak
}

\author{
Jody Inggil Pambudi, Endah Wahyuni dan Ananta Sigit Sidharta \\ Departemen Teknik Sipil, Fakultas Teknik Sipil dan Perencanaan, Institut Teknologi Sepuluh Nopember (ITS) \\ e-mail: ananta@ce.its.ac.id
}

\begin{abstract}
Abstrak-Bangunan mesin kiln merupakan bangunan mesin yang berfungsi untuk mengolah material mentah menjadi material siap pakai. Material yang diolah pada mesin kiln ini adalah material batu kapur yang diolah menjadi senyawa kimia untuk keperluan industri. Perencanaan pondasi apabila harus menopang beban berupa mesin, maka pondasi tersebut dipengaruhi oleh beban yang bergetar, beban ini disebabkan oleh gaya-gaya mesin yang tidak seimbang dan beban statis sistem (pondasi dan mesin).Pada mesin kiln pembakaran digunakan pondasi dinamis tipe pedestal, pondasi ini berupa struktur beton bertulang dengan ketinggian tertentu yang terdiri dari balok dan kolom yang ditumpu oleh pondasi slab. Bagian atas dari kolom dihubungkan dengan top slab sehingga membentuk lantai untuk meletakan mesin. Metode pekerjaan untuk membangun pondasi tipe pedestal ini adalah metode cast in situ.Pada Studi ini akan dimodifikasi metode pekerjaannya dengan metode pracetak, diharapkan Studi ini mendapatkan hasil yang lebih efisien dan tepat guna, ditinjau dari kondisi lapangan yang ada. Melihat kondisi di lapangan yang berada di daerah pegunungan, membuat akses untuk menuju area proyek sulit dijangkau. Penggunaan alat berat, perancah, dan bekesting dapat diminimalkan dengan penggunaan metode pracetak. Mutu dari struktur juga terjamin karena proses pembuatan elemen struktur pracetak dapat dihindarkan dari kondisi alam dilapangan.
\end{abstract}

Kata Kunci-Bangunan, Mesin Kiln, Beban Dinamis, Pondasi, Pracetak.

\section{PENDAHULUAN}

\section{A. Latar Belakang}

Kabupaten Tuban adalah salah satu kabupaten di Jawa Timur yang terletak di pantai utara Jawa Timur. Terdapat banyak sektor perekonomian di Kabupaten Tuban, salah satunya adalah pengolahan batu kapur, yang banyak terdapat di kecamatan plumpang. Teknologi pengolahan batu kapur disana masih menggunakan pengolahan tradisional, dari bangunan dan mesin pembakarannya. Kebutuhan oalahan batu kapur semakin hari semakin meningkat, dan pengolahan tradisional dirasa tidak cukup untuk memenuhi kebutuhan tersebut. PT Pentawira Agraha Sakti merupakan perusahaan pengolahan batu kapur yang terdapat di kecamatan Plumpang yang berencana meningkatkan teknologi pengolahan batu kapur dengan membangun mesin kiln berteknologi modern.

Bangunan kiln merupakan bangunan pembakaran untuk mengolah material mentah menjadi material olahan siap pakai. Bangunan kiln ini merupakan bangunan yang menampung mesin kiln yang bekerja membakar batu kapur. Batu kapur dibakar di mesin kiln untuk mengolahnya menjadi olahan batu kapur. Dengan menggunakan mesin kiln dengan teknologi modern ini dirasa dapat memenuhi kebutuhan terhadap olahan batu kapur.
Perencaan bangunan kiln memperhatikan getaran yang disebabkan oleh beban statis dan beban dinamis yang terjadi pada saat mesin beroperasi [1]. Getaran yang berlebihan dapat menyebabkan struktur utama dan pondasi, sehingga diperlukan perencaan untuk meredam getaran yang berlebihan.

Pembangunan bangunan kiln tersebut menggunakan metode cast in situ. Pembangunan dirasa kurang cepat dan efisien. Dalam proses pengerjaan kondisi baja tulangan yang sedang dilakukan proses pembesian mengalami perkaratan pada permukaannya. Terjadi penambahan biaya akibat sewa alat untuk pekerjaan yang terlambat akibat kondisi lapangan yang sering hujan.

Dari permasalahan yang ada, maka pada Studi ini akan dilakukan modifikasi pada bangunan mesin kiln PT Pentawira Aghara Sakti dengan metode pracetak (precast) yang sebelumnya menggunakan metode cast in situ. Pembangunan diharapkan dapat lebih efeisien dan cepat dari proses pembangunan sebelumnya. Mutu dari elemen struktur bangunan juga lebih terjamin.

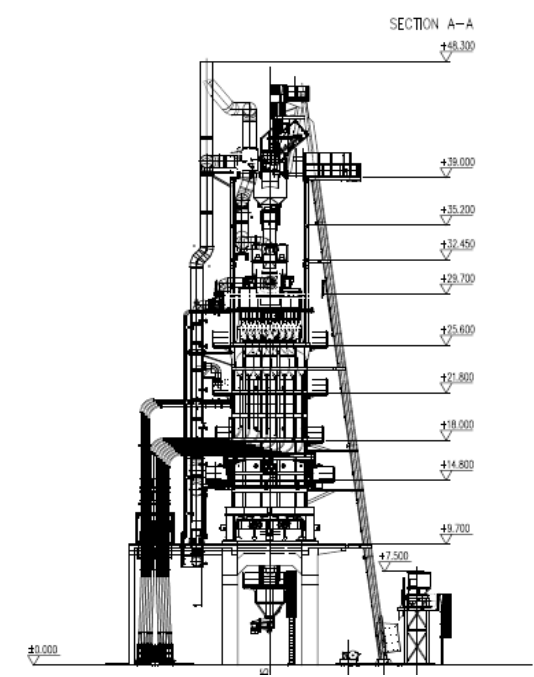

Gambar 1. Kiln Pembakaran.

\section{B. Tujuan Umum}

Tujuan dari perencanaan ini adalah mampu merencanakan struktur bangunan mesin kiln dengan menggunakan metode pracetak dengan perencanaan sambungan yang monolit, dan juga mampu merencakan struktur bangunan mesin kiln yang dapat menopang beban statis dan dinamis akibat mesin yang bekerja.

\section{Batasan Masalah}

Batasan dalam modifikasi perencanaan struktur bangunan kiln PT Pentawira Aghara Sakti, meliputi

1. Dalam perancangan struktur ini direncanakan penggunaan teknologi pracetak hanya pada bagian balok 
induk, balok anak, dan pelat, sedangkan untuk kolom menggunakan sistem cor setempat (cast in situ).

2. Tidak menghitung RAB bangunan.

3. Perancangan tidak meliputi utilitas bangunan, mekanikal, instalasi listrik, dan finishing.

4. Program bantu yang dipakai meliputi SAP2000, PCACol, dan AutoCAD.

\section{TINJAUAN PUSTAKA}

Bangunan mesin kiln menopang beban lateral dari berat statis mesin dan juga menerima beban dinamik akibat gerak mesin yang bekerja. Pada mesin pembakaan terdapan beban dinamik yang besar akibat sistem rotary mesin vibrating extractor [2]. Struktur bangunan ini diharapkan mampu menahan beban mesin yang bekerja dan juga mampu menahan beban aksial serta beban gempa yang terjadi.

Pada proses pembakaran terjadi perpindahan panas dari temperature tinggi mesin ke temperature rendah pada bangunan, pemilihan bahan beton diharapkan mampu menahan perpindahan panas mesin agar struktur tidak mengalami penurunan kekuatan.

Pada mesin blower room juga mengalami beban dinamik mesin tetapi tidak sebesar beban dinamik yang dialami mesin pembakaran. Diperlukan perencanaan pondasi dinamis untuk menopang beban dinamis yang bekerja pada bangunan mesin kiln pembakaran dan blower room.

Untuk pondasi yang menahan beban dinamis ini cara perhitungannya jelas berbeda dengan pondasi yang hanya menahan beban statis, dimana harus memperhatikan adanya beban dinamis akibat kerja mesin selain beban statis yang ada. Meskipun gaya dinamis yang membebani pondasi mesin relative kecil dibandingkan gaya statisnya, gaya dinamis ini tidak dapat diabaikan dalam perhitungan karena gaya tersebut bekerja berulang dan beroperasi dalam waktu cukup lama.

Metode Analisa Akibat Beban Dinamis

Ada 3 metode yang dapat digunakan dalam perhitungan amplitudo dan frekuensi pada pondasi mesin [3] yaitu:

1. Metode Linear Elastic Weightless Spring Method.

2. Metode Elastic Half - Space.

3. Metode Lumped Parameter System.

Struktur utama direncanakan menggunakan metode pracetak untuk mempercepat pelaksanaan dan menjaga mutu dari elemen -elemen struktur.

Beton pracetak adalah beton yang diproduksi dalam bentuk yang spesifik di lokasi selain posisi layan elemen tersebut. Beton tersebut dibentuk di dalam cetakan dari kayu atau baja dan dirawat sebelum kemudian dilepas dari cetakan pada waktu tertentu. Lalu, komponen pracetak dipindahkan menuju lokasi konstruksi dan dipasang menuju posisi layannya. Beton pracetak diberi perkuatan dengan tulangan maupun tendon mutu tinggi. Jenis komponen beton pracetak yang biasa diproduksi antara lain: panel dinding, balok dobel-T, pelat lantai hollow, kolom \& balok, komponen jembatan, dan lain-lain [4].

Sambungan ini merupakan sambungan dengan menggunakan tulangan biasa sebagai penyambung / penghubung antar elemen beton baik antar pracetak ataupun antara pracetak dengan cor setempat. Elemen pracetak yang sudah berada di tempatnya akan di cor bagian ujungnya untuk menyambungkan elemen satu dengan yang lain agar menjadi satu kesatuan yang monolit. Sambungan jenis ini disebut dengan sambungan basah. Sambungan jenis ini sering diterapkan dalam pelaksanaan konstruksi, karena tergolong mudah dalam pelaksanaannya. Selain itu sambungan ini dapat membuat bangunan menjadi lebih kaku dibanding menggunakan sambungan jenis lain. Dalam modifikasi ini akan direncanakan menggunakan sambungan cor setempat.

\section{METODOLOGI}

Urutan penyelesaian Studi ini dapat dilihat pada bagan alir dibawah ini:

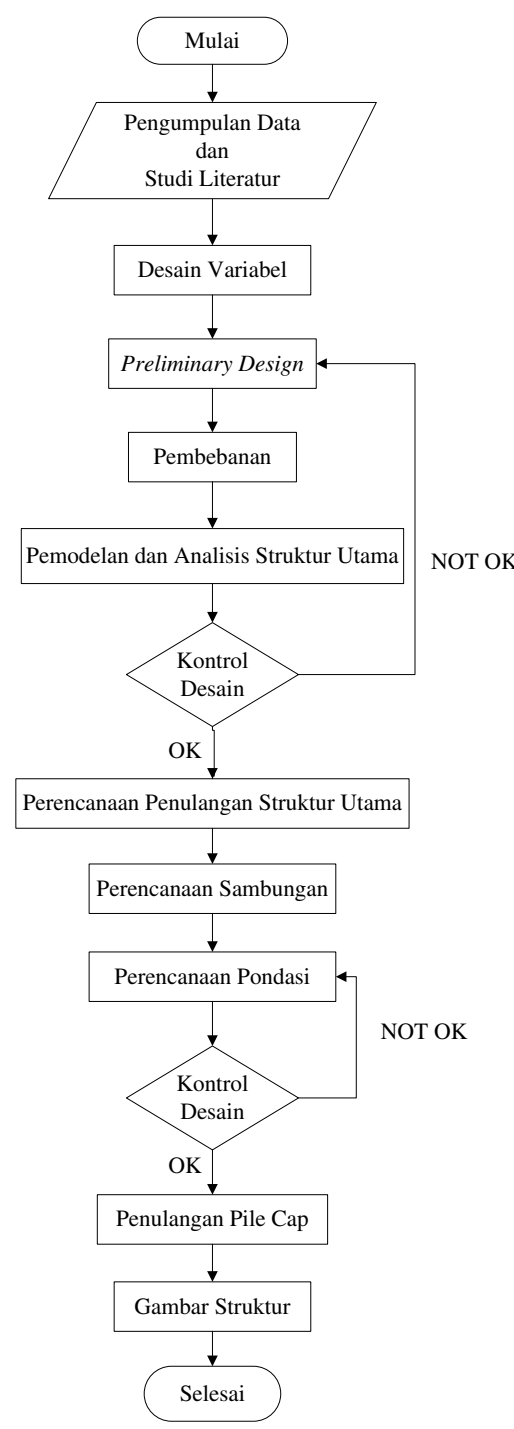

Gambar 2. Diagram Alir Penyelesaian Studi.

\section{HASIL DAN PEMBAHASAN}

\section{A. Preliminary Design}

1. Rencana modifikasi

- Nama Gedung Pentawira Aghara Sakti

- Lokasi Rencana Kabupaten Tuban

- Fungsi

- Struktur Utama : Beton Bertulang

- Metode : Pracetak

- Tinggi Bangunan : 48,3 m

- Rencana Pondasi : Spun Pile

2. Data mesin 


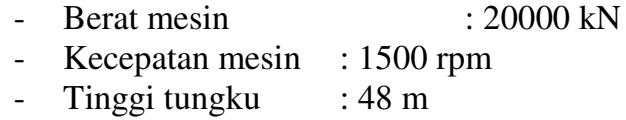

\section{A.1 Perencenaan Dimensi Balok Induk}

Dimensi balok yang disyaratkan [5] yang tertera pada Tabel 1 adalah sebagai berikut:

$$
\mathrm{h}_{\min }=\frac{1}{16} \times \mathrm{L}_{\mathrm{b}}
$$

Untuk lebar balok diambil 2/3 dari tinggi balok :

$$
b=\frac{2}{3} \times h
$$

Tabel 1.

Rekapitulasi Dimensi Balok Induk

\begin{tabular}{ccccc}
\hline \hline Kode & Letak & $\begin{array}{c}\text { Lb } \\
(\mathrm{cm})\end{array}$ & $\begin{array}{c}\text { Dimensi } \\
(\mathrm{cm})\end{array}$ & Jumlah \\
\hline BI 1 & Blower Room & 940 & $40 / 60$ & 8 \\
BI 2 & Blower Room & 705 & $40 / 60$ & 4 \\
BI 3 & Blower Room & 580 & $40 / 60$ & 20 \\
BI 4 & Blower Room & 570 & $40 / 60$ & 6 \\
BI 5 & Mesin Kiln & 781 & $125 / 190$ & 2 \\
BI 6 & Mesin Kiln & 633 & $120 / 180$ & 2 \\
BI 7 & Mesin Kiln & 740 & $70 / 100$ & 2 \\
BI 8 & Mesin Kiln & 781 & $70 / 100$ & 1 \\
\hline \hline
\end{tabular}

\section{A.2 Perencanaan Dimensi Balok Anak}

Dimensi balok yang disyaratkan [5] yang tertera pada Tabel 2 adalah sebagai berikut:

$$
\mathrm{h}_{\min }=\frac{1}{16} \times \mathrm{L}_{\mathrm{b}}
$$

Untuk lebar balok diambil 2/3 dari tinggi balok :

$$
b=\frac{2}{3} \times h
$$

Tabel 2.

Rekapitulasi Dimensi Balok Anak

\begin{tabular}{ccccc}
\hline \hline Kode & Letak & $\begin{array}{c}\text { Lb } \\
(\mathrm{cm})\end{array}$ & $\begin{array}{c}\text { Dimensi } \\
(\mathrm{cm})\end{array}$ & Jumlah \\
\hline BA1 & Blower Room & 580 & $20 / 30$ & 24 \\
BA2 & Blower Room & 570 & $20 / 30$ & 6 \\
BA3 & Blower Room & 300 & $20 / 30$ & 6 \\
BA4 & Mesin Kiln & 633 & $100 / 150$ & 1 \\
BA5 & Mesin Kiln & 781 & $40 / 60$ & 1 \\
BL & Mesin Kiln & 200 & $40 / 60$ & 9 \\
\hline \hline
\end{tabular}

\section{A.3 Perencanaan Tebal Pelat Pracetak}

Direncanakan pelat lantai dan atap dengan total tebal pelat yaitu $12 \mathrm{~cm}$. Adapun spesifikasi tebal pelat pracetak dengan tebal $8 \mathrm{~cm}$ dan overtopping $4 \mathrm{~cm}$.

\begin{tabular}{|c|c|c|c|c|c|c|}
\hline Tipe & Letak & $\begin{array}{c}\mathrm{Ly} \\
(\mathrm{cm})\end{array}$ & $\begin{array}{c}\mathrm{Lx} \\
(\mathrm{cm})\end{array}$ & $\beta$ & Ket. & $\begin{array}{c}\text { h pakai } \\
(\mathrm{cm})\end{array}$ \\
\hline P1 & $\begin{array}{l}\text { Blower } \\
\text { Room }\end{array}$ & 580 & 235 & 2,6 & 1 arah & 12 \\
\hline $\mathrm{P} 2$ & $\begin{array}{l}\text { Blower } \\
\text { Room }\end{array}$ & 570 & 235 & 2,5 & 1 arah & 12 \\
\hline P3 & $\begin{array}{l}\text { Blower } \\
\text { Room }\end{array}$ & 570 & 170 & 3,5 & 1 arah & 12 \\
\hline P4 & $\begin{array}{l}\text { Blower } \\
\text { Room }\end{array}$ & 300 & 135 & 2,7 & 1 arah & 12 \\
\hline P5 & $\begin{array}{c}\text { Mesin } \\
\text { Kiln }\end{array}$ & 780 & 390 & 2,1 & 1 arah & 12 \\
\hline P6 & $\begin{array}{l}\text { Mesin } \\
\text { Kiln }\end{array}$ & 385 & 200 & 2,1 & 1 arah & 12 \\
\hline P7 & $\begin{array}{l}\text { Mesin } \\
\text { Kiln }\end{array}$ & 335 & 200 & 2,1 & 1 arah & 12 \\
\hline P8 & $\begin{array}{l}\text { Mesin } \\
\text { Kiln }\end{array}$ & 633 & 200 & 2,1 & 1 arah & 12 \\
\hline P9 & $\begin{array}{l}\text { Mesin } \\
\text { Kiln }\end{array}$ & 428 & 200 & 2,1 & 1 arah & 12 \\
\hline
\end{tabular}

Data perencanaan pelat sebagai berikut :

Tabel 3.

Rekapitulasi Dimensi Pelat

\begin{tabular}{lcccccc}
\hline \hline P10 & $\begin{array}{c}\text { Mesin } \\
\text { Kiln }\end{array}$ & 200 & 200 & 1 & 2 arah & 12 \\
\hline \hline
\end{tabular}

\section{A.4 Perencanaan Dimensi Kolom}

Dimensi kolom yang disyaratkan [5] yang tertera pada

Tabel 4 adalah sebagai berikut:

Tabel 4.

Rekapitulasi Dimensi Kolom

\begin{tabular}{cccc}
\hline \hline Kode & Letak & $\mathrm{b}(\mathrm{cm})$ & $\mathrm{h}(\mathrm{cm})$ \\
\hline K1 & Blower Room & 80 & 50 \\
K2 & Mesin Kiln & 220 & 125 \\
K3 & Mesin Kiln & 70 & 70 \\
\hline \hline
\end{tabular}

\section{B. Permodelan Struktur}

\section{B.1 Kontrol Partisipasi Massa}

Partisipasi massa harus menyertakan jumlah ragam terkombinasi minimal $90 \%$ dari massa aktual yang berasal dari masing-masing arah horizontal dan orthogonal yang ditinjau [6].

Tabel 5.

Kontrol Nilai Partisipasi Massa

\begin{tabular}{ccccc}
\hline \hline OutputCase & Mode & Period & SumUX & Sum UY \\
\hline Text & Text & Sec & Unitless & Unitless \\
Mode & 1 & 0.242342 & 0.9978 & 0.00024 \\
Mode & 2 & 0.21595 & 0.99923 & 0.24221 \\
Mode & 3 & 0.152799 & 0.99925 & 0.99816 \\
\hline \hline
\end{tabular}

\section{B.2 Kontrol Waktu Getar Alami Fundamental}

Perhitungan waktu getar alami fundamental menggunakan rumusan [6] berikut :

$$
\begin{aligned}
& T=C_{u} \times T_{a} \\
& T=1,4 \times 0,3601 d t \\
& T=0,5042 d t
\end{aligned}
$$

Tabel 6.

Kontrol Waktu Getar Alami Fundamental Blower Room

\begin{tabular}{llll}
\hline \hline OutputCase & StepType & StepNum & Period \\
\hline Text & Text & Unitless & Sec \\
MODAL & Mode & 1 & 0.423967 \\
\hline \hline
\end{tabular}

Tabel 7.

Kontrol Waktu Getar Alami Fundamental Mesin Kiln

\begin{tabular}{llll}
\hline \hline OutputCase & StepType & StepNum & Period \\
\hline Text & Text & Unitless & Sec \\
MODAL & Mode & 1 & 0.242342 \\
\hline \hline
\end{tabular}

Dari tabel diatas $\mathrm{Tc}=0,5042 \mathrm{~s}$, maka berdasarkan kontrol aktu getar alami fundamental, nilai $\mathrm{T}$ masih lebih kecil dari Cu.T. Jadi analisis struktur memenuhi syarat.

B.3 Kontrol Nilai Akhir Respon Spektrum

Kombinasi respons untuk gaya geser dasar ragam dinamik (Vt) harus lebih besar $85 \%$ dari gaya geser dasar statik (V) atau $\left(\mathrm{V}_{\text {dinamik }} \geq 0,85 \mathrm{~V}_{\text {statik }}\right)$ [6].

$$
\begin{aligned}
& C_{s}=0,044 \cdot S_{D S} \cdot I_{e} \\
& C_{s}=0,044 \times 0,563 \times 1 \\
& C_{s}=0,0247 \\
& \mathrm{~W}=5.319,54 \mathrm{KN} \\
& V=C_{s} \times W \\
& V=0,0247 \times 7.119,2 \mathrm{KN} \\
& V=176,46 \mathrm{KN}
\end{aligned}
$$


Tabel 12

Maka untuk arah $\mathrm{x}$,

$$
V_{x t}>0,85 \mathrm{~V}
$$

$149,993 K N>0,85 \times 176,46 K N$

$149,993 K N>149,992 K N \ldots$ "OK"

Maka untuk arah $\mathrm{y}$,

$$
V_{y t}>0,85 \mathrm{~V}
$$

$149,994 K N>0,85 \times 176,46 K N$

$149,994 K N>149,992 K N \ldots$ "OK"

\section{B.4 Kontrol Simpangan (Drift)}

Gempa menyebabkan struktur bertingkat rawan terhadap terjadinya simpangan horizontal (Drift). Dan apabila simpangan horizontal ini melebihi syarat aman yang telah ditentukan maka gedung akan mengalami keruntuhan [6]

\section{$>$ Kontrol Simpangan Arah-Y Gempa Arah Y}

Tabel 8.

Gempa Arah X

\begin{tabular}{ccccccc}
\hline \hline \multirow{2}{*}{ Tingkat } & $\mathrm{hi}$ & $\delta \mathrm{xe}$ & $\delta \mathrm{x}$ & $\operatorname{Drift}(\Delta \mathrm{nx})$ & Syarat $\Delta \mathrm{a}$ & \\
\cline { 2 - 6 } & $\mathrm{m}$ & $\mathrm{m}$ & $\mathrm{m}$ & $\mathrm{m}$ & $\mathrm{m}$ & \\
1 & 9.7 & 0.0005 & 0.00275 & 0.00275 & 0.02425 & OK \\
\hline \hline
\end{tabular}

Tabel 9.

Gempa Arah Y

\begin{tabular}{ccccccc}
\hline \hline Tingkat & hi & $\delta y e$ & $\delta y$ & $\begin{array}{c}\text { Drift } \\
(\Delta \mathrm{nx}) \\
\mathrm{m}\end{array}$ & $\begin{array}{c}\text { Syar } \\
\text { at } \Delta \mathrm{a} \\
\mathrm{m}\end{array}$ & Ket \\
\hline 1 & 9.7 & 0.000397 & 0.002184 & 0.002183 & $\begin{array}{c}0.024 \\
25\end{array}$ & OK \\
\hline \hline
\end{tabular}

\section{Perhitungan Struktur Sekunder}

\section{C.1 Perhitungan Balok Anak}

Hasil perhitungan balok anak sesuai persyaratan [5] tertera pada Tabel 10 dan Tabel 11.

Tabel 10.

Rekapitulasi Penulangan Terpasang pada Balok Anak Blower Room

\begin{tabular}{|l|c|c|c|c|c|c|}
\hline KODE & \multicolumn{2}{|c|}{ BALOK ANAK1 } & \multicolumn{2}{c|}{ BALOK ANAK 2 } & \multicolumn{2}{c|}{ BALOK ANAK 3 } \\
\hline PANJANG & \multicolumn{2}{|c|}{580} & \multicolumn{2}{c|}{570} & \multicolumn{2}{c|}{300} \\
\hline KONDISI & TUMPUAN & LAPANGAN & TUMPUAN & LAPANGAN & TUMPUAN & LAPANGAN \\
\hline PENAMPANG BALOK (CM) & 30 & 40 & 30 & 40 & 30 & 40 \\
\hline DECKING (MM) & \multicolumn{2}{|c|}{40} & \multicolumn{2}{c|}{40} & \multicolumn{2}{c|}{40} \\
\hline ATAS & $2 D 29$ & $2 D 29$ & $2 D 29$ & $2 D 29$ & $2 D 29$ & $2 D 29$ \\
\hline TENGAH & $2 D 29$ & - & $2 D 29$ & - & $2 D 29$ & - \\
\hline BAWAH & $2 D 29$ & $2 D 29$ & $2 D 29$ & $2 D 29$ & $2 D 29$ & $2 D 29$ \\
\hline BEGEL & $2 D 10-100$ & $2 D 10-200$ & $2 D 10-100$ & $2 D 10-200$ & $2 D 10-100$ & $2 D 10-200$ \\
\hline
\end{tabular}

Tabel 11.

Rekapitulasi Penulangan Terpasang pada Balok Anak Mesin Kiln

\begin{tabular}{|l|c|c|c|c|c|c|c|}
\hline KODE & \multicolumn{2}{|c|}{ BALOKANAK 4 } & \multicolumn{2}{c|}{ BALOKANAK5 } & \multicolumn{2}{c|}{ BALOK LEUVEL } \\
\hline PANJANG (CM) & \multicolumn{2}{|c|}{633} & \multicolumn{2}{c|}{781} & \multicolumn{2}{c|}{200} \\
\hline KONDISI & TUMPUAN & LAPANGAN & TUMPUAN & LAPANGAN & TUMPUAN & LAPANGAN \\
\hline PENAMPANG BALOK (CM) & 100 & 150 & 40 & 60 & 40 & 60 \\
\hline DECKING (MM) & \multicolumn{2}{|c|}{40} & \multicolumn{2}{c|}{40} & \multicolumn{2}{c|}{40} \\
\hline ATAS & 9029 & $9 D 29$ & $4 D 29$ & 2 D29 & 4 D29 & 2 D29 \\
\hline TENGAH & $9 D 29$ & - & $2 D 29$ & - & 2 D29 & - \\
\hline BAWAH & $9 D 29$ & $9 D 29$ & $2 D 29$ & $2 D 29$ & 2 D29 & 2 D29 \\
\hline BEGEL & 2 D13-100 & 2 D13-200 & 2 D13-100 & 2 D13-200 & 2 D13-100 & 2 D13-200 \\
\hline
\end{tabular}

\section{C.2 Perhitungan Pelat}

Hasil perhitungan pelat sesuai persyaratan [5] tertera pada Tabel 12 dan Tabel 13.
Rekapitulasi Penulangan Terpasang pada Pelat Blower Room

\begin{tabular}{|c|c|c|c|c|c|c|c|}
\hline \multirow{2}{*}{ Tipe Pelat } & \multicolumn{2}{|c|}{ Ukuran pelat $(\mathrm{cm})$} & \multicolumn{2}{|c|}{ Tulangan Terpasang } & \multirow{2}{*}{ Stud } & $\begin{array}{c}\text { Panjang } \\
\text { Penyaluran }\end{array}$ & $\begin{array}{c}\text { Tulangan } \\
\text { Angkat }\end{array}$ \\
\cline { 2 - 5 } & panjang & lebar & $\begin{array}{c}\text { Tulangan } \\
\text { Utama }\end{array}$ & $\begin{array}{c}\text { Tulangan } \\
\text { pembagi }\end{array}$ & & Demb & \\
\hline P1 (PARSIAL) & 206 & 100 & D10 - 300 & D10 - 350 & D10 - 150 & 150 & D10 \\
\hline P2 (PARSIAL) & 211 & 100 & D10 - 300 & D10 - 350 & D10 - 150 & 150 & D10 \\
\hline P3 (PARSIAL) & 206 & 100 & D10 - 300 & D10 - 350 & D10 - 150 & 150 & D10 \\
\hline P4 (PARSIAL) & 211 & 100 & D10 - 300 & D10 - 350 & D10 - 150 & 150 & D10 \\
\hline P5 & 536 & 146 & D10 - 300 & D10 - 300 & D10 - 150 & 150 & D10 \\
\hline P6 & 271 & 110 & D10 - 300 & D10 - 300 & D10 - 150 & 150 & D10 \\
\hline
\end{tabular}

Tabel 13.

Rekapitulasi Penulangan Terpasang pada Pelat Mesin Kiln

\begin{tabular}{|c|c|c|c|c|c|c|c|}
\hline \multirow{2}{*}{ Tipe Pelat } & \multicolumn{2}{|c|}{ Ukuran pelat $(\mathrm{cm})$} & \multicolumn{2}{|c|}{ Tulangan Terpasang } & \multirow{2}{*}{ Panjang } & Tulangan \\
\cline { 2 - 5 } & panjang & lebar & $\begin{array}{c}\text { Tulangan } \\
\text { Utama }\end{array}$ & $\begin{array}{c}\text { Tulangan } \\
\text { pembagi }\end{array}$ & & Penyaluran & Angkat \\
\hline P7 (parsial) & 370 & 100 & D10 - 300 & D10 - 350 & D10 - 150 & 150 & D10 \\
\hline P8 (parsial) & 385 & 100 & D10 - 300 & D10 - 350 & D10 - 150 & 150 & D10 \\
\hline P9 (parsial) & 335 & 100 & D10 - 300 & D10 - 350 & D10 - 150 & 150 & D10 \\
\hline P10 & 633 & 200 & D10 - 300 & D10 - 350 & D10 - 150 & 150 & D10 \\
\hline P11 & 428 & 200 & D10 - 300 & D10 - 350 & D10 - 150 & 150 & D10 \\
\hline P12 & 200 & 200 & D10 - 300 & D10 - 300 & D10 - 150 & 150 & D10 \\
\hline
\end{tabular}

\section{Perhitungan Struktur Primer}

\section{D.1 Balok Induk}

Hasil perhitungan balok induk sesuai persyaratan [5] tertera pada Tabel 14 .

Tabel 14.

Rekapitulasi Balok Induk

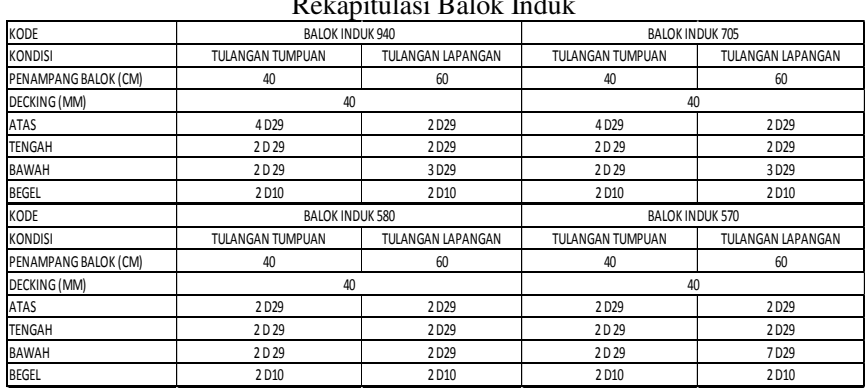

\section{D.2 Kolom}

Hasil perhitungan kolom sesuai persyaratan [5] tertera pada Tabel 15.

Tabel 15.

Rekapitulasi Kolom

\begin{tabular}{|l|c|c|c|c|c|c|}
\hline KODE & \multicolumn{2}{|c|}{ KOLOM 1 } & \multicolumn{2}{c|}{ KOLOM 2 } & \multicolumn{2}{c|}{ KOLOM3 } \\
\hline PENAMPANG KOLOM(CM) & 50 & 80 & 125 & 220 & 70 & 70 \\
\hline TULANGAN & 8 D29 & 8 D29 & 96 D36 & 96 D36 & 8 D29 & 8 D29 \\
\hline BEGEL & D16 - 100 & D16 - 150 & D16 - 100 & D16 - 150 & D16 - 100 & D16 - 150 \\
\hline
\end{tabular}

\section{E. Perencanaan Sambungan}

\section{E.1 Sambungan Balok Induk - Kolom}

Sambungan pada balok induk dan kolom dibantu oleh konsol pendek untuk menopang balok induk sebelum dsambungkan.

Tabel 16.

\begin{tabular}{|c|c|c|c|c|c|c|c|c|c|c|c|c|}
\hline \multirow[b]{2}{*}{ Sambungan } & \multirow[b]{2}{*}{$\begin{array}{c}\mathrm{Vu} \\
(\mathrm{kN})\end{array}$} & \multirow[b]{2}{*}{$\begin{array}{c}\mathrm{Nu} \\
(\mathrm{kN})\end{array}$} & \multicolumn{2}{|c|}{ Ukuran } & \multirow[b]{2}{*}{$\begin{array}{c}\emptyset \mathrm{s} \\
(\mathrm{mm})\end{array}$} & \multirow[b]{2}{*}{$\begin{array}{c}\emptyset \mathrm{h} \\
(\mathrm{mm})\end{array}$} & \multicolumn{3}{|c|}{ Horizontal } & \multicolumn{3}{|c|}{ Sengkang } \\
\hline & & & $b(\mathrm{~mm})$ & $h(\mathrm{~mm})$ & & & \begin{tabular}{|c|} 
As \\
$\left(\mathrm{mm}^{2}\right)$ \\
perlu \\
\end{tabular} & $\begin{array}{c}\text { As } \\
\left(\mathrm{mm}^{2}\right) \\
\text { pakai } \\
\end{array}$ & $\begin{array}{c}\mathrm{n} \\
\text { (buah) }\end{array}$ & \begin{tabular}{|c|} 
Ah \\
$\left(\mathrm{mm}^{2}\right)$ \\
perlu \\
\end{tabular} & \begin{tabular}{c|c|} 
Ah \\
$\left(\mathrm{mm}^{2}\right)$ \\
pakai \\
\end{tabular} & \begin{tabular}{|c|}
$\mathrm{n}$ \\
(buah) \\
\end{tabular} \\
\hline & 248.87 & 49.77 & 400 & 200 & 16 & 10 & 891.93 & 1005.3 & 5 & 360.88 & 392.70 & 5 \\
\hline Kolom K1 - BI 2 & 248.87 & 49.77 & 400 & 200 & 16 & 10 & 891.93 & 1005.3 & 5 & 360.88 & 392.70 & 5 \\
\hline
\end{tabular}

Rekapitulasi Konsol 


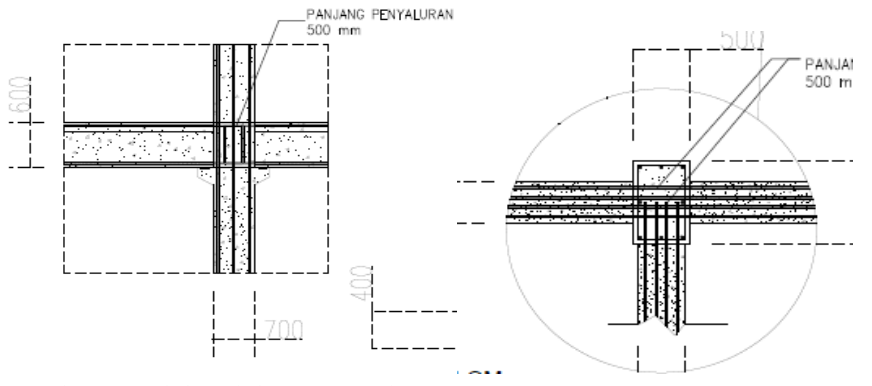

Gambar 3. Balok Induk BI 1 - Kolom K1.

\section{E.2 Sambungan Balok Anak - Balok Induk}

Sambungan balok anak dan balok induk digunakan $N M B$ Splice Sleeve berupa coupler dan SS Mortar yang berupa inject grouting.

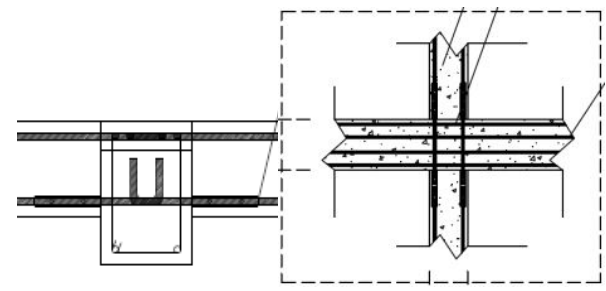

Gambar 4. Balok Induk BI 1 - Kolom K1.

\section{F. Perhitungan Struktur Bawah}

\section{F.1 Pondasi Tiang Pancang}

Pondasi [7] yang digunakan pada perencanaan bangunan kiln berasal dari tiang pancang beton (Concrete Pile) dari produk dari PT. WIKA Beton dengan spesifikasi adalah sebagai berikut:

- Diameter tiang - kedalaman : $400 \mathrm{~mm}-22 \mathrm{~m}$

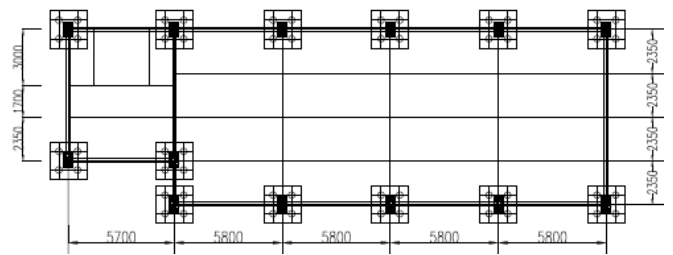

Gambar 5. Denah Pondasi.

\section{F.2 Pondasi Dinamis}

Beban mesin yang bekerja harus direncanakan agar struktur bisa menahan gaya dinamis dari mesin, maka dari itu harus direncanakan sesuai dengan cara kerja mesin tersebut [1].

Dimana :

$$
F o=m \times e \times \omega^{2}
$$

$$
\begin{array}{ll}
\mathrm{m} & =\text { massa rotor mesin } \\
\mathrm{e} & =\text { eksentrisitas dari rotor } \\
& =\alpha \times \sqrt{12000 / r p m} \leq 1.0 \mathrm{mil} \text { (API Standart) } \\
\omega & =2 \times \pi \times(f / 60) \\
f & =\text { frekuensi mesin }(\mathrm{rpm})
\end{array}
$$

Perencanaan pondasi dinamis

Dimensi pile cap : $15 \mathrm{~m}$ x $3 \mathrm{~m}$ x $1 \mathrm{~m}$

\begin{tabular}{|c|c|c|c|}
\hline \multicolumn{2}{|c|}{ Amplitudo Vertikal } & \multicolumn{2}{|c|}{ Amplitudo Uncoupled Rocking } \\
\hline$\omega n z$ & 6.773872858 & $\omega n z$ & 26.79854403 \\
\hline $\mathrm{Dz}$ & 0.036748627 & $\mathrm{Dz}$ & 1414.131672 \\
\hline$r$ & 23.18904355 & $\mathrm{r}$ & 5.861498763 \\
\hline $\mathrm{M}$ & 0.001863119 & $M$ & 0.0000603 \\
\hline $\mathrm{Az}$ & 0.000318464 & $\mathrm{Az}$ & 0.0000001 \\
\hline & \multicolumn{2}{|c|}{ Amplitudo Lateral } & \\
\hline & $\omega n z$ & 0.721589532 & \\
\hline & Dz & 0.036591262 & \\
\hline & $r$ & 217.6855757 & \\
\hline & M & 0.00002 & \\
\hline & $\mathrm{Az}$ & 0.00031788 & \\
\hline
\end{tabular}

Jumlah tiang : 18 buah

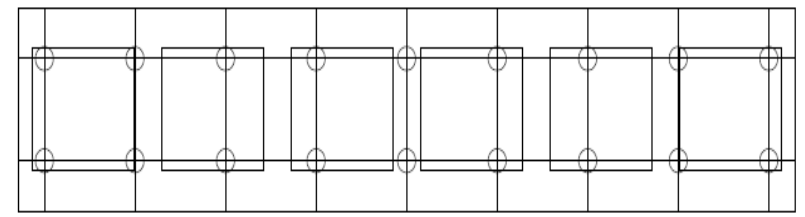

Gambar 6. Pondasi Dinamis.
Tabel 17.

Perhitungan Amplitudo Vertikal, Lateran, Rocking

1. Cek kondisi Pondasi

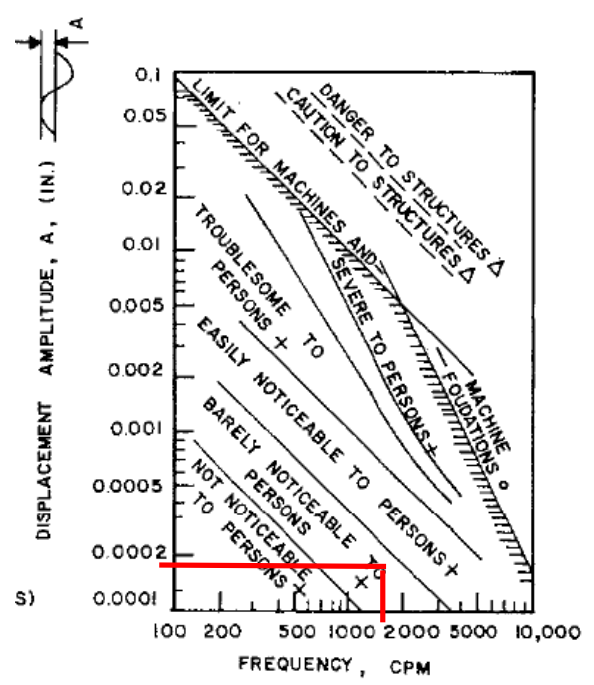

Gambar 7. Kategori desain masuk pada "Barely Noticeable to Person”. [1]

2. Isolasi Aktif

- $\quad V_{S}=\sqrt{\frac{G \times g}{\gamma t}}$

$V=\sqrt{\frac{19709,65 \times 9,8}{1,66}}$

- $V_{S}=341,11 \mathrm{~m} / \mathrm{s}$

$V_{R}=V \times V_{S}$

$V_{R}=0,943 \times 341,11$

$V_{R}=321,66 \mathrm{~m} / \mathrm{s}$

- $\quad \lambda_{R}=\frac{V_{R}}{f_{\text {mesin }}}$

$\lambda_{R}=\frac{321,66}{25}$

$\lambda_{R}=12,86 m$

3. Syarat Isolasi Aktif

$$
\Theta=360 \longrightarrow \frac{H}{\lambda_{R}} \geq 0,60
$$

4. Mencari Kedalaman Galian

Kedalaman galian didapat berdasarkan persyaratan [8] yaitu :

$$
\begin{aligned}
& H=0,6 \times \lambda_{R} \\
& H=0,6 \times 12,86 \\
& H=7 \mathrm{~m}
\end{aligned}
$$




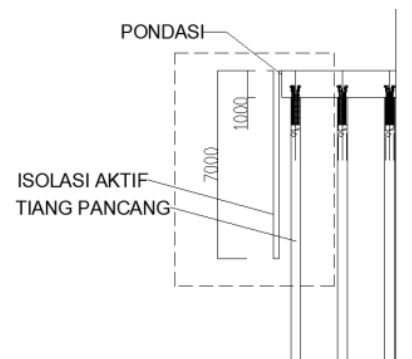

Gambar 8. Isolasi Aktif Getaran.

\section{KESIMPULAN DAN SARAN}

\section{A. Kesimpulan}

1. Berdasarkan SNI 2847:2013 didapatkan perhitungan tebal dimensi struktur sekunder dan struktur primer dari struktur yang direncanakan.

2. Perencanaan bangunan kiln telah sesuai dengan syarat peratura yang digunakan.

3. Penyambungan elemen pracetak bersidat monolit dang menggunakan sambungan basah berupa overtopping pada sambungan balok - pelat, kepala kolom (balok kolom) dan produk sambungan dai NMB Splice Sleeve berupa coupler dan SS Mortar yang berupa inject grouting pada balok anak - balok induk, balok induk kolom (mesin kiln)

4. Pondasi yang direncanakan sesuai dengan ketentuan perhitungan tiang pancang (spun pile) produk dari WIKA Beton dengan metode tengangan ijin dan pile cap (poer) berdasarkan metode tengangan ultimate.

5. Pondasi yang menopang beban kerja mesin direncanakan agar gaya kerja mesin tidak mempengaruhi struktur utama. Penggunaan isolasi getaran digunakan untuk meredam getaran yang terjadi.

\section{B. Saran}

Berdasarkan analisa secara keseluruhan dari proses penyusunan Studi ini, beberapa saran yang dapat disampaikan oleh penulis diantaranya adalah :

1. Urutan yang benar dalam perencanaan gedung dengan metode pracetak adalah menentukan design gambar 3D, menentukan kriteria design dan konsep desain sambungan. Hal ini dikarenakan hal terpenting dalam perencanaan metode beton pracetak adalah konsep yang dimiliki, karena untuk perhitungan hampir sama dengan metode konvensional.

2. Dalam pelaksanaan di lapangan terutama pada bagian pengangkatan elemen pracetak dan sambungan antar elemen pracetak harus diberi pengawasan yang baik dan benar. Dalam pengangkatan harus diperhatikan tinggi angkat dan sudut pengangkatan agar tidak terjadi kegagalan struktur akibat momen tak terduga saat pengangkatan. Pada saat penyambungan, tentunya sambungan beton pracetak tidak semonolit sambungan cor setempat dan rawan terjadi keretakan akibat gayagaya yang tidak diinginkan karena kurang sempurnanya pekerjaan sambungan.

3. Perancangan elemen yang akan dipracetak seharusnya bisa dibuat lebih efisien jika memperhatikan konsep desain terlebih dahulu. Dalam pengembangan ke depannya elemen dinding geser bisa dibuat pracetak jika memenuhi ketentuan dalam peraturan yang ada.

\section{DAFTAR PUSTAKA}

[1] S. C. Arya, M. W. O’Neil, and G. Pincus, Design of Structure: Analysis Foundation for Vibrating Machines. USA: Gulf Publishing Company, 1979.

[2] J. E. Bowles, Analisis dan Desain Pondasi, Terjemahan. Jakarta: Erlangga, 1993.

[3] S. Prakash and P. V. K., Foundation for Machine: Analysis and Design. New York: John Wiley \& Sons, 1988.

[4] Precast/Prestressed Concrete Institute, PCI Design Handbook Precast and Prestressed Concrete. Chicago: PCI Industry Handbook Committee, 2004

[5] Badan Standardisasi Nasional, "SNI 03-2847-2013 Tata cara Perhitungan Struktur Beton Untuk Bangunan Gedung," Jakarta, 2013.

[6] Badan Standarisasi Nasional, "Tata Cara Perencanaan Ketahanan Gempa Untuk Bangunan Gedung (SNI 03-1726-2012),' Bandung, 2012.

[7] H. Wahyudi, Daya Dukung Pondasi Dalam. Surabaya: Jurusan Teknik Sipil FTSP - ITS, 1999.

[8] B. M. Das, Pondasi Tanah Dinamis. Jakarta: Erlangga, 1984. 